\title{
The role of gravitational instabilities in deposition of volcanic
}

ash

Irene Manzella ${ }^{1}$, Costanza Bonadonna ${ }^{1}$, Jeremy Phillips $^{2}$ and Hélène Monnard ${ }^{1}$

${ }^{1}$ Section of Earth and Environmental Sciences, University of Geneva, rue des Maraîchers 13, 1205 Geneva, Switzerland

${ }^{2}$ School of Earth Sciences, University of Bristol, Wills Memorial Building, Queen's Road, Bristol BS8 1RJ, UK 


\section{Complementary field data}

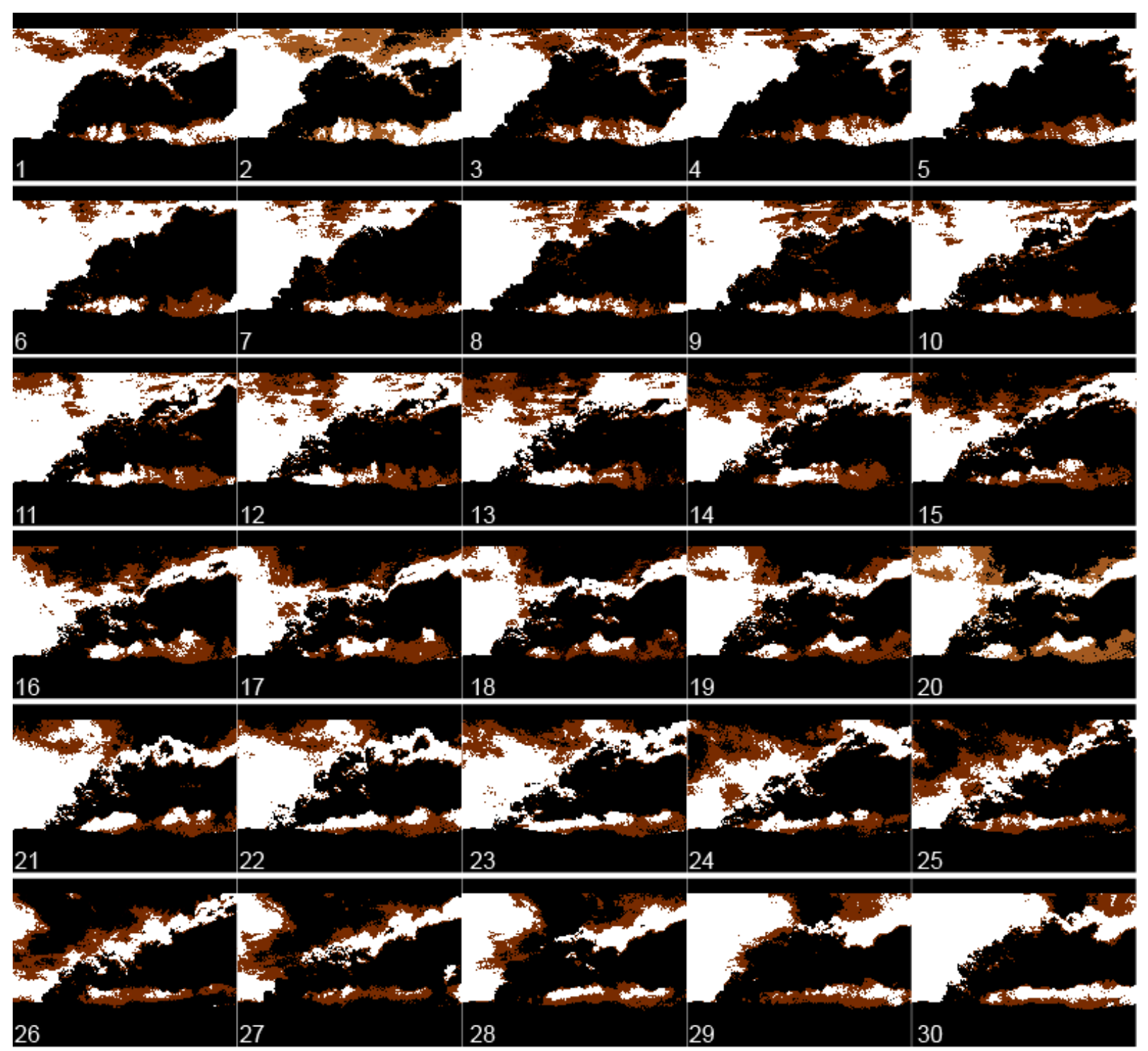

Fig. DR1 Processed snapshots for each minute of the video of the Eyafjallajökull eruption, 4th May 2010.

These snapshots are a low definition version of the ones used for measuring the data shown in Fig. DR2. 

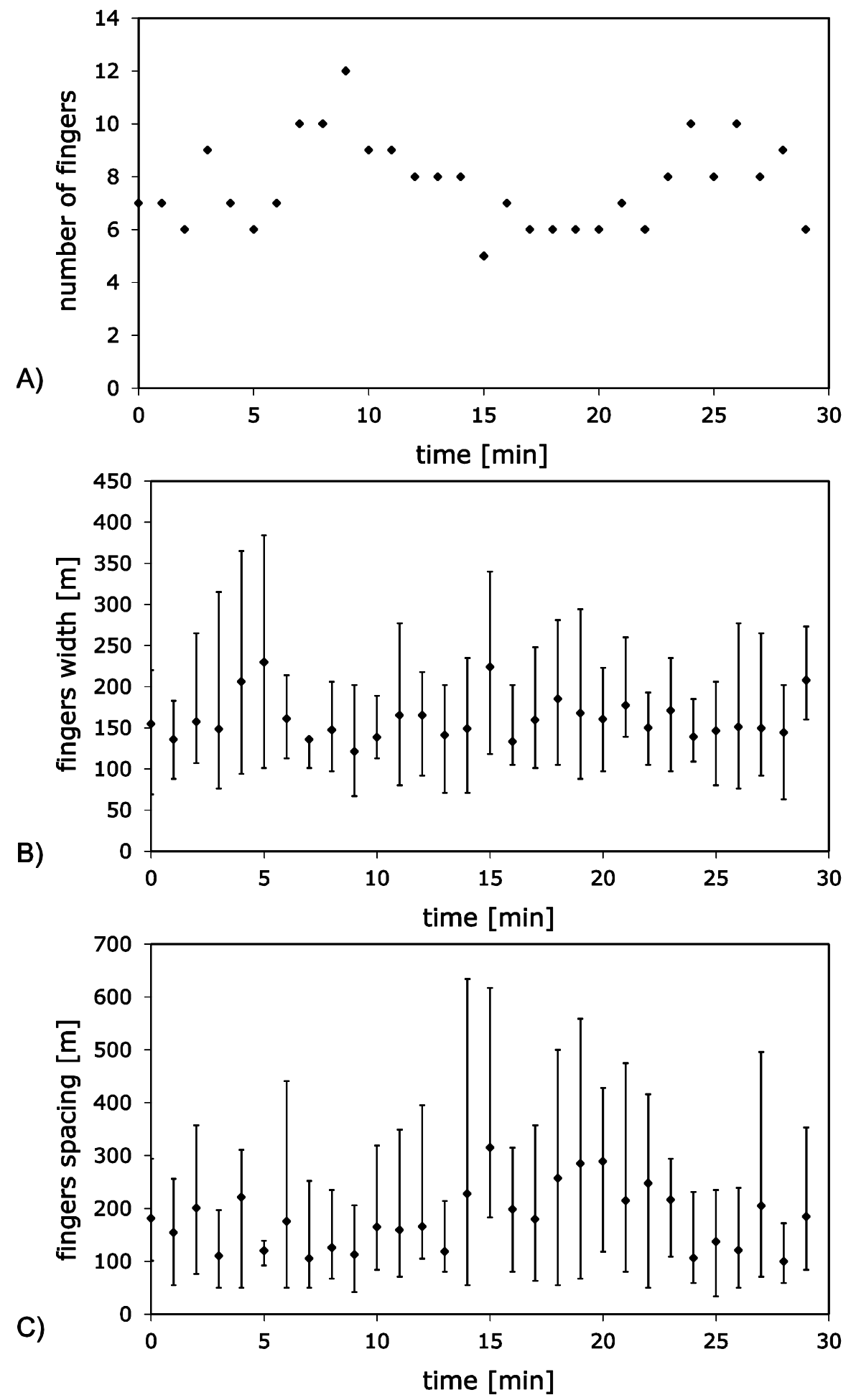

Fig. DR2 Eyafjallajökull eruption of the 4th May 2010: finger width (B) and spacing (C) averaged among all the fingers at each time step (1 minute, see Fig. DR1) observed across the whole field-of-view. The bar represents the range of the corresponding parameter. 

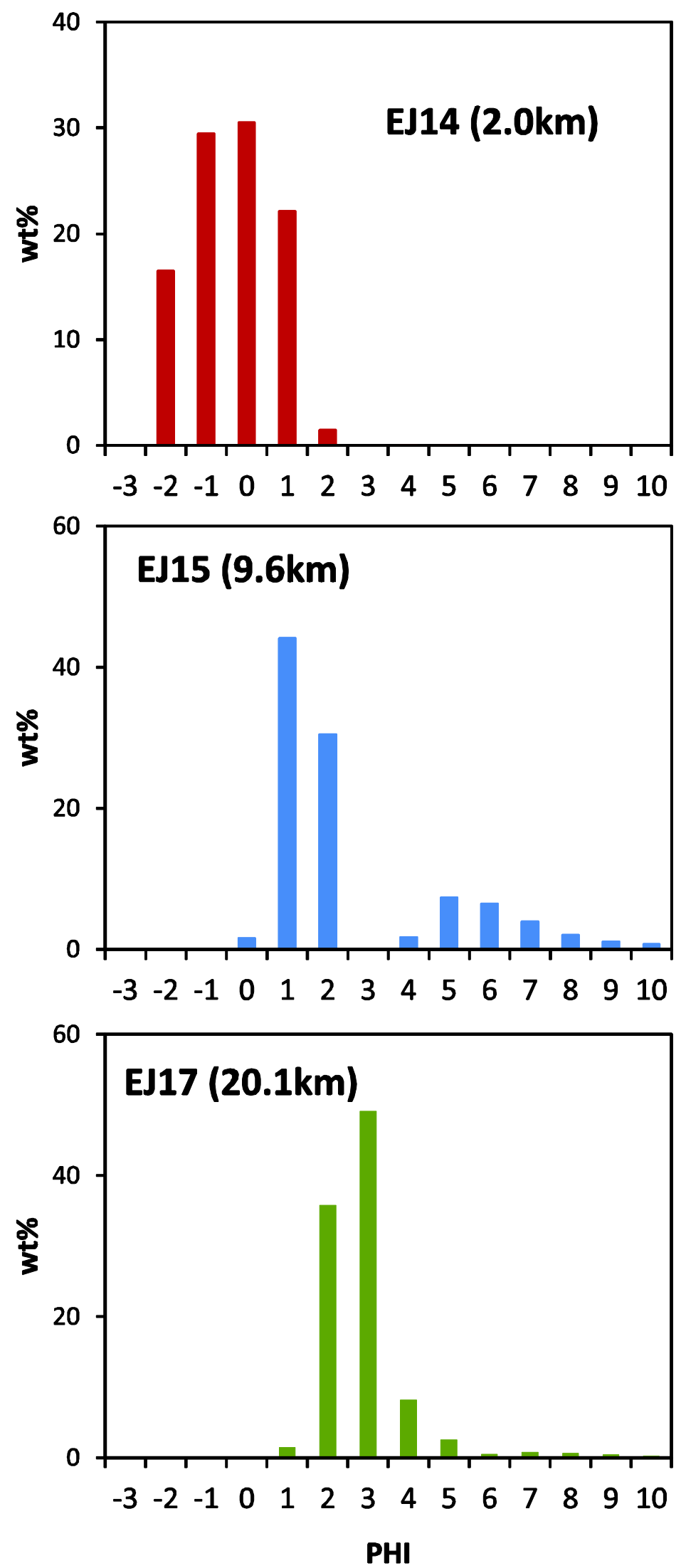

Fig. DR3 Grain-size distribution (adjusted from Bonadonna et al. (2011)) at: a) $2 \mathrm{~km}$, b) $10 \mathrm{~km}$ and c) 20 km from the vent of Eyafjallajökull volcano 


\section{Experimental Method and Scaling}

The experimental configuration is similar to that of previous studies (Hoyal et al., 1999; Linden and Redondo, 1991) with an aqueous suspension of water and spherical glass beads (manufacturer; particle density $=2550 \mathrm{~kg} / \mathrm{m}^{3}$ ) initially overlying a higher density sugar solution, with both solutions containing small quantities of Calgon deflocculant. The experiments were conducted in a Plexiglas tank of $50 \mathrm{~cm}$ height $\times 30.3 \mathrm{~cm}$ width $\mathrm{x} 30 \mathrm{~cm}$ depth with a removable horizontal barrier positioned $25.1 \mathrm{~cm}$ above the tank base (see Fig. DR4). For these experiments the depth of the tank was restricted to $7.5 \mathrm{~cm}$ by the insertion of vertical plexiglass plates above and below the barrier to form a false back wall. The barrier was made from a flexible PET sheet that moved between recessed guides in the tank side walls, which were horizontal across the depth of the tank, and which curved to vertical orientation behind the false back wall, to allow the sheet to be removed from the tank top (see Figure DR4).

At the start of the experiment, the upper layer was either quiescent (i.e. no external forcing of the suspension, but with particles fully suspended by previous stirring) or continually mixed using a rotary stirrer, and the experiment was initiated by the removal of the horizontal barrier (see Fig. DR5). The plate was withdrawn slowly from the tank top, to open the horizontal gap between the upper and lower layers which extended $7.5 \mathrm{~cm}$. In this way, minimal disturbance to the layers resulted, and the timescale of opening was short with respect to that of finger formation (Parsons et al., 2001), thus shear between the layers was negligible.

The laboratory experiments are conducted with a fixed volume of water and particles, and fingers propagate vertically downwards below the upper layer. In the field, the volcanic ash cloud and the fingers are both moving horizontally at the wind speed, and the fingers propagate vertically downwards below the ash cloud (Figures 1 and DR1). The experiments thus mimic this behaviour in a Galilean frame moving at the wind speed. In both the experiments and the field (in the sense of moving at the wind speed), there is no net horizontal supply of particles into the destabilising PBL. Over the timescale of finger propagation, there is no significant net vertical supply of particles into the PBL from the overlying suspension due to the low settling speed of the particles. The continually-mixed experiments mimic the turbulent dynamics found within a volcanic plume. Following Hoyal et al. (1999), in our experiments, stirring was kept at a low angular velocity, only just sufficient to ensure good mixing of the particles in the upper layer (as confirmed by the good agreement with the 
turbulent upper layer model, see Fig. DR6), but with negligible entrainment of the lower fluid. The regions of the tank where measurements were made were limited to the zones where these edge effects were minimized (Linden and Redondo, 1991), excluding zones close to the stirrer and the contours of the upper and lower layers.

During the experiments, temperature remains constant over the whole tank, and the diffusivity of sugar is relatively low (diffusion coefficient $=0.5 \times 10^{-5} \mathrm{~cm}^{2} / \mathrm{s}$ ), so that settling is the dominant process causing gravitational instabilities (Hoyal et al., 1999). The sugar solution was used to ensure that the lower layer density exceeded the bulk density of the upper layer (to avoid large scale convective overturn) and had a constant density of $1008.4 \mathrm{~kg} / \mathrm{m}^{3}$, as compared to upper layer densities of $1000.0,1000.6$ and $1001.2 \mathrm{~kg} / \mathrm{m}^{3}$, for particle concentrations of 3,4 and $5 \mathrm{~kg} / \mathrm{m}^{3}$, respectively.

The initial density of the particle suspension in the upper layer is calculated by:

$$
\rho_{1}=\left(\frac{\left(1-x_{p}\right)}{\rho_{l}}+\frac{x_{p}}{\rho_{p}}\right)^{-1}
$$

where $\rho_{l}\left(\mathrm{~kg} / \mathrm{m}^{3}\right)$ is the density of the fluid without particles, $\rho_{\mathrm{p}}\left(\mathrm{kg} / \mathrm{m}^{3}\right)$, is the particle density and $x_{p}$ is the volume fraction of particle. The particle size distribution is characterised by mean diameter of $45 \mu \mathrm{m}$, and 10th and 90th percentiles of $33 \mu \mathrm{m}$ and $63 \mu \mathrm{m}$, respectively. The experimental tank was backlit and filmed using high-resolution video from the front, to allow the evolution of concentration in each layer to be measured using calibrated pixel intensity levels.

The dynamic conditions in the experiments are similar to those for ash particles and finger instabilities in volcanic ash clouds. In the experiments, the particle settling speeds for diameters from 33 to $63 \mu \mathrm{m}$, i.e respectively 10th and 90th percentiles, are $8.8 \times 10^{-4}$ to $3.2 \mathrm{x}$ $10^{-3} \mathrm{~m} / \mathrm{s}$, which is less than the finger speed (consistent with finger formation) of respectively between 10.4 to $13.5 \times 10^{-3} \mathrm{~m} / \mathrm{s}$ computed according to the equation 1 in the manuscript.

The particle Reynolds number is 0.03 to 0.2 , consistent with Stokes settling. The particle Stokes numbers are about $2 \times 10^{-4}$ in the propagating fingers in the laboratory, which is in the broad range assessed by Carazzo and Jellinek (2012) for natural umbrella clouds. In both cases $\mathrm{St}<<1$, which means that particles remain coupled to the motion of the fluid. Following 
Carazzo and Jellinek (2012), we calculated the Sedimentation number $\Sigma$ as approximately 2 in our laboratory experiments, in the broad range of volcanic ash clouds and in a regime where there is a strong two-way coupling between fluid and particles (Carazzo and Jellinek, 2012). The finger Reynolds number attainable in the experiment was of order 100, so as for the field case, the dynamics are not viscously-dominated. The particle volumetric concentration in the experiments was of order $10^{-9}$ as compared to $10^{-6}$ for the field, so both suspensions are highly dilute. Grashof numbers are of order $10^{8}$, which is lower than estimates for the field in the range $10^{15}-10^{20}$ (Carazzo and Jellinek 2012) but still significantly above $10^{3}$ where balance between buoyancy and other viscous forces is similar.

The tank was illuminated by two light sources (tube soft lights, flicker-free high frequency, full spectrum lamps) sited each side of the tank at a distance of $80 \mathrm{~cm}$ and centred in its middle height to uniformly light up the fluid. The particle-laden fluid appears bright in front of a dark background. Images were recorded with a high speed-high definition camera camera (PHANTOM V10), where the field-of-view was 1440x976 pixels and the frame rate was 20 images per seconds as a compromise between definition and recording time.

A process of calibration has been carried out to correlate the different grey levels of a film image to different levels of concentration. This has been done by analyzing images of the tank filled with suspension of fluid and particles with known concentration, from 0 to $5 \mathrm{~kg} / \mathrm{m}^{3}$ with a $0.25 \mathrm{~kg} / \mathrm{m}^{3}$ step. For higher precision, the calibration curves have been derived separately for the lower and upper part and both areas have been further divided in 8 rows and 8 columns to account for any differences in lighting along the tank. In the case of the mixed experiments, the area with the stirrer has not been considered. Based on the calibration the mean concentration has been calculated for each of the 64 zones of the upper and of the lower part and the total concentration of the two layers is an average of the 64 values. This measuring method gives some problems for low concentration, i.e. near $0 \mathrm{~kg} / \mathrm{m}^{3}$, where it is difficult to distinguish between the grey levels of the images with few suspended particles. As a consequence, the error of this measure varies with the concentration of particles, reaching a maximum of $0.38 \mathrm{~kg} / \mathrm{m}^{3}$ estimated for concentration near $0 \mathrm{~kg} / \mathrm{m}^{3}$. This value has been thus used for the error limits shown in the plots in Fig.3, Fig. DR6 and Fig. DR7. In addition, this method is very sensitive even to slight changes in the light emplacement and intensity and for this reason a large number of experimental runs were necessary to obtain reliable measures. 

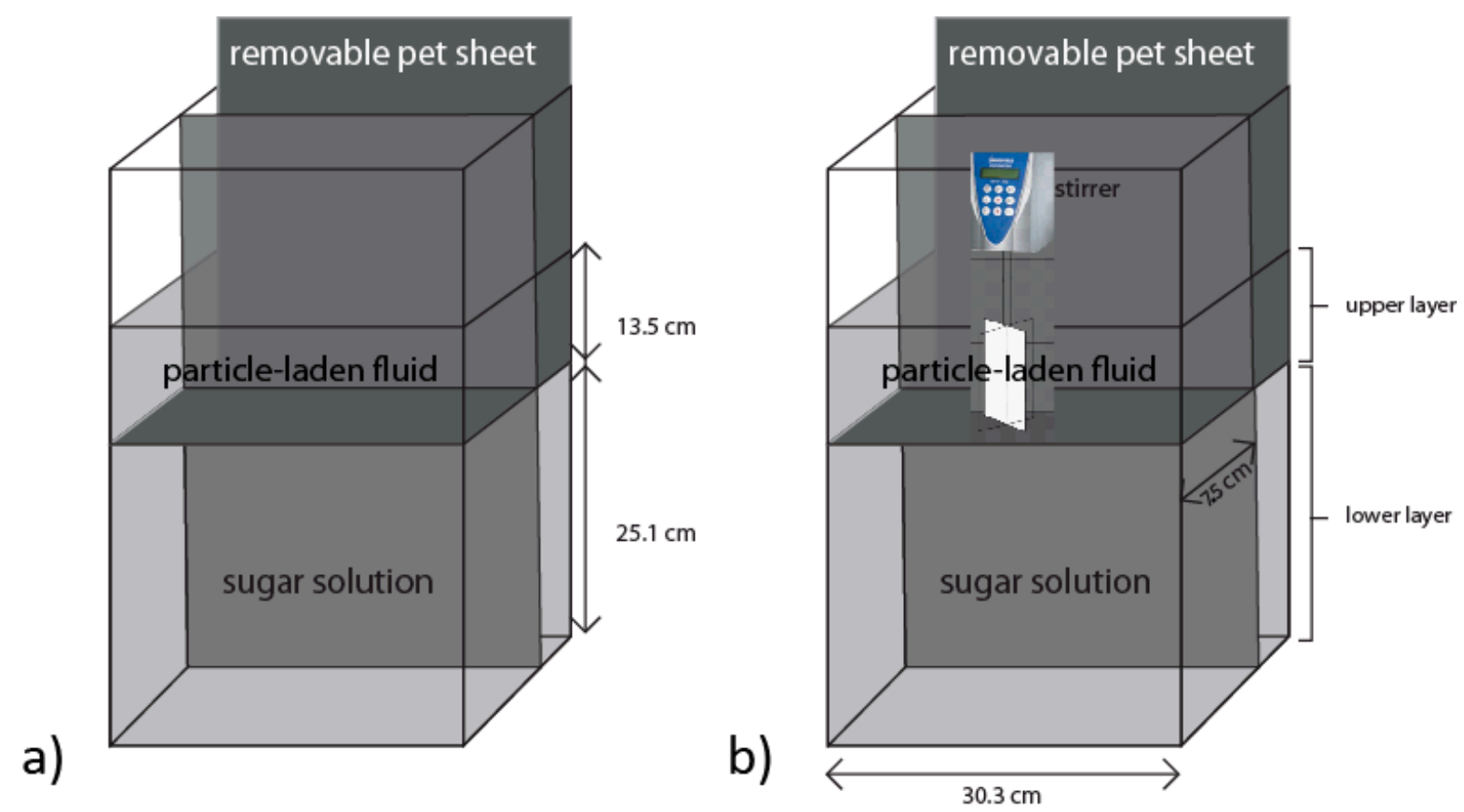

Fig. DR4 Experimental set-up for a) unmixed and b) mixed experiments. 


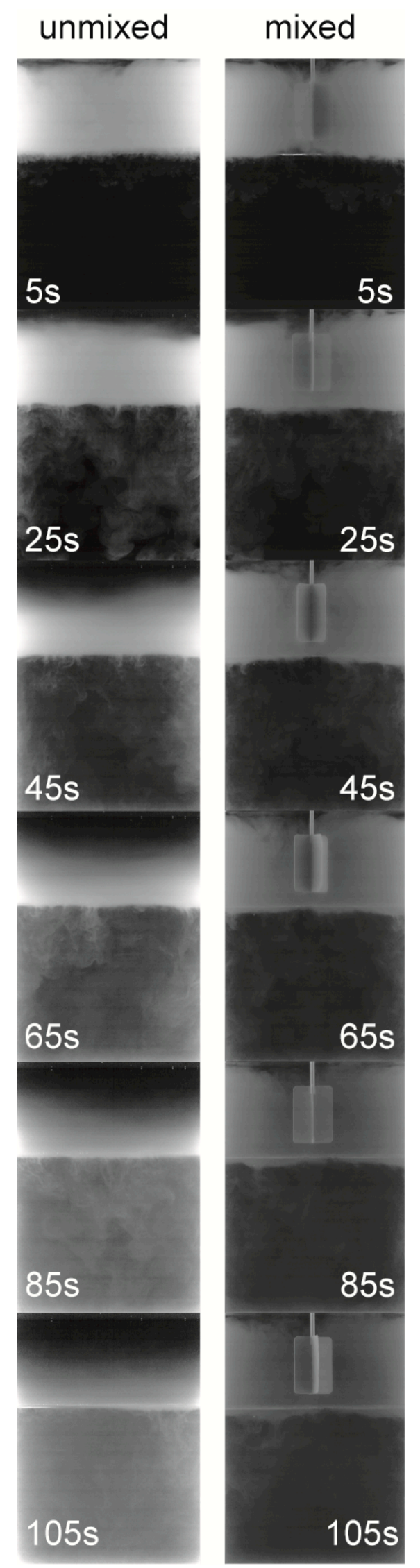

Fig. DR5 Snapshots of the video of unmixed and mixed experiments. $C_{0}=5 \mathrm{~kg} / \mathrm{m}^{3}$ 

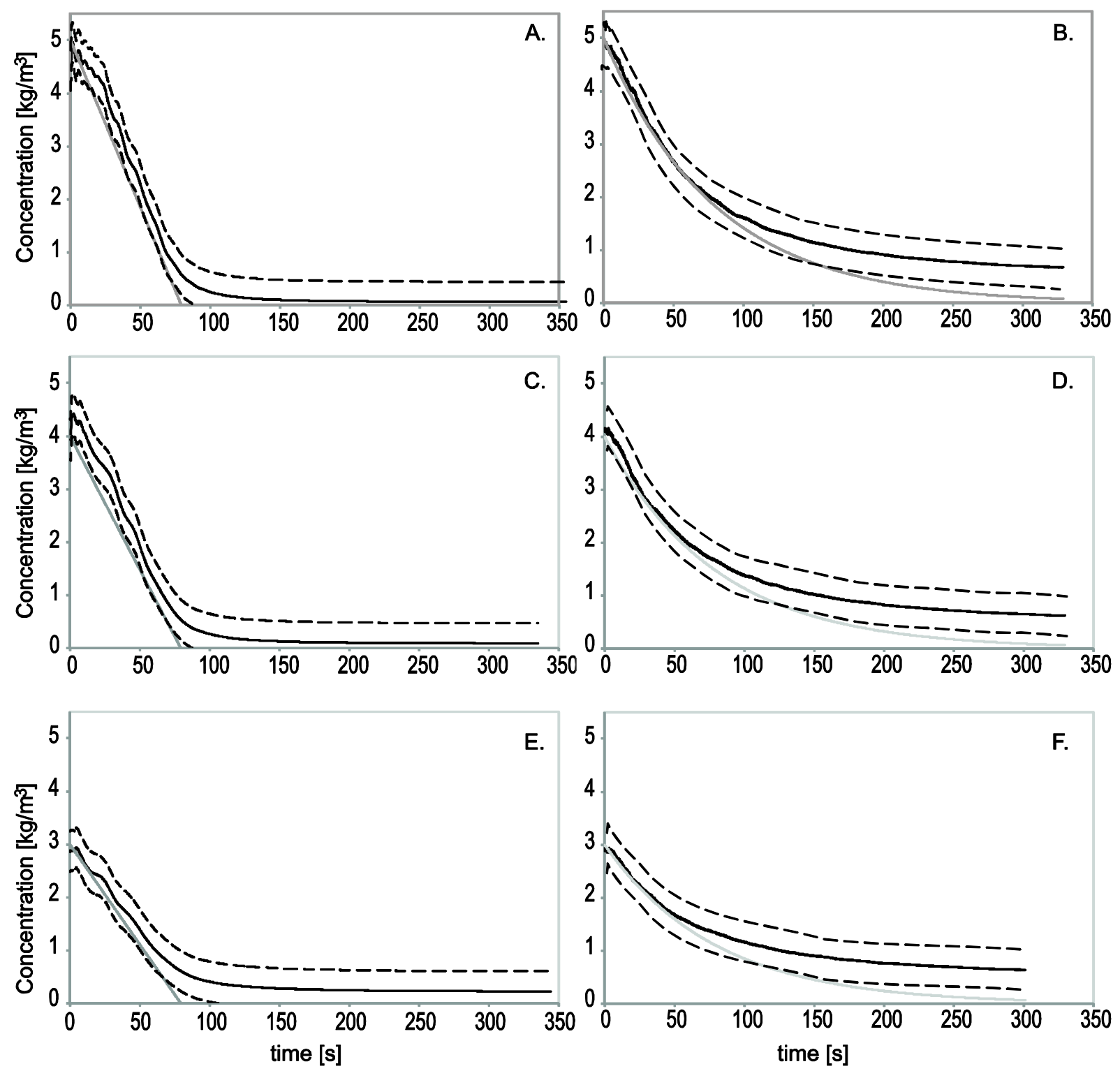

Fig. DR6 Average concentration versus time in the upper layer for unmixed (A, C, E) and mixed (B,D,F) experiments (solid black line), for $\mathrm{C}_{0}=5 \mathrm{~kg} / \mathrm{m}^{3}$ (A,B), $4 \mathrm{~kg} / \mathrm{m}^{3}$ (C,D), $3 \mathrm{~kg} / \mathrm{m}^{3}$ (E,F); error limits are shown with dashed line. Data are compared with the quiescent and turbulent model (solid grey line) of Hoyal et al. (1999) 

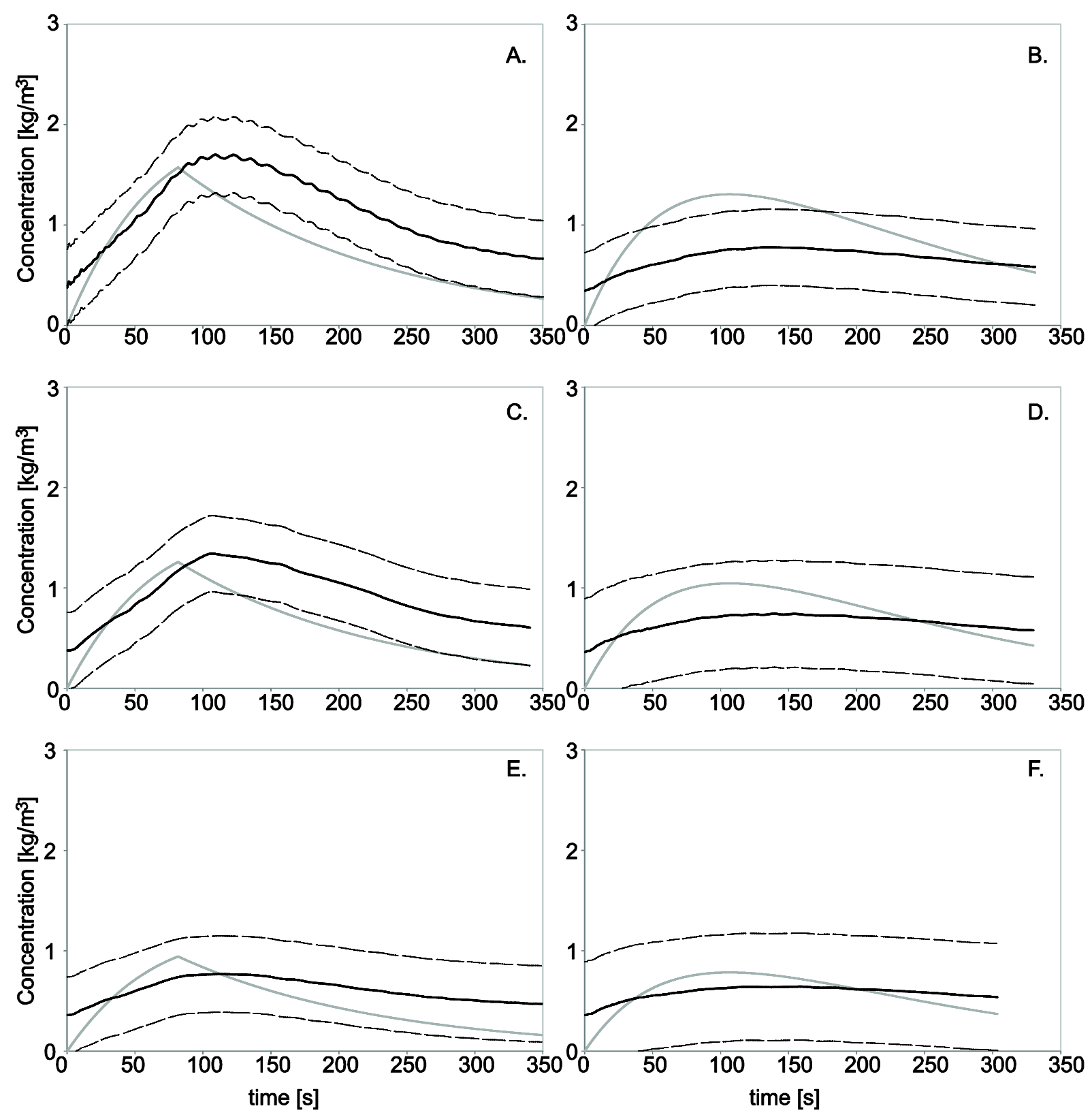

Fig. DR7 Average concentration versus time in the lower layer for unmixed (A, C, E) and mixed (B,D,F) experiments (solid black line), for $\mathrm{C}_{0}=5 \mathrm{~kg} / \mathrm{m}^{3}(\mathrm{~A}, \mathrm{~B}), 4 \mathrm{~kg} / \mathrm{m}^{3}(C, D), 3 \mathrm{~kg} / \mathrm{m}^{3}(\mathrm{E}, \mathrm{F})$; error limits are shown with dashed line. Data are compared with the quiescent- convective model in equation $\mathbf{2}$ in the manuscript and the turbulent- convective model (solid grey line) of Hoyal et al. (1999)

Table DR1 Finger vertical velocity measured for unmixed and mixed experiments, $C_{0}=5 \mathrm{Kg} / \mathrm{m}^{3}$, compared to the one computed with equation 1 of the manuscript assuming D50, i.e. $45 \mu \mathrm{m}$, as the particle diameter

\begin{tabular}{|c|c|c|c|c|}
\hline & \multicolumn{2}{|c|}{$5 \mathrm{~kg} / \mathrm{m}^{3}$ unmixed } & \multicolumn{2}{|c|}{$5 \mathrm{~kg} / \mathrm{m}^{3}$ mixed } \\
\hline & Measured & Computed & Measured & Computed \\
\hline Finger vertical velocity $[\mathrm{m} / \mathrm{s}]$ & $8.2 \pm 1.4 \times 10^{-3}$ & $11.7 \times 10^{-3}$ & $5.9 \pm 1.3 \times 10^{-3}$ & $11.7 \times 10^{-3}$ \\
\hline
\end{tabular}




\section{References}

Bonadonna, C., Genco, R., Gouhier, M., Pistolesi, M., Cioni, R., Alfano, F., Hoskuldsson, A., and Ripepe, M., 2011, Tephra sedimentation during the 2010 Eyjafjallajökull eruption (Iceland) from deposit, radar, and satellite observations: Journal of Geophysical Research: Solid Earth, v. 116, no. B12, p. B12202, doi: 10.1029/2011JB008462

Carazzo, G., and Jellinek, A. M., 2012, A new view of the dynamics, stability and longevity of volcanic clouds: Earth and Planetary Science Letters, v. 325, p. 39-51, doi: 10.1016/j.epsl.2012.01.025

Hoyal, D. C. J. D., Bursik, M. I., and Atkinson, J. F., 1999, Settling-driven convection: A mechanism of sedimentation from stratified fluids: Journal of Geophysical Research-Oceans, v. 104, no. C4, p. 7953-7966, doi: 10.1029/1998JC900065

Linden, P. F., and Redondo, J. M., 1991, Molecular mixing in Rayleigh-Taylor instability .1. Global mixing: Physics of Fluids a-Fluid Dynamics, v. 3, no. 5, p. 1269-1277, doi: $10.1063 / 1.858055$

Parsons, J. D., Bush, J. W. M., and Syvitski, J. P. M., 2001, Hyperpycnal plume formation from riverine outflows with small sediment concentrations: Sedimentology, v. 48, no. 2, p. 465-478, doi: 10.1046/j.1365-3091.2001.00384.x 